\title{
Impact of Flax Seed Powder Supplementation on the Anthropometry and Bio-chemical Parameters of Dyslipidemic Patients
}

\author{
Deepika Sharma ${ }^{1 *}$ and Nimali Singh ${ }^{2}$ \\ ${ }^{1}$ Research Scholar, Department of Home Science, University of Rajasthan, Jaipur, \\ India \\ ${ }^{2}$ Associate Professor, Department of Home Science, University of Rajasthan, Jaipur, \\ India
}

*Corresponding Author: Deepika Sharma, Research Scholar, Department of Home Science, University of Rajasthan, Jaipur, India.
Received: July 08, 2021

Published: August 28, 2021

(C) All rights are reserved by Deepika Sharma and Nimali Singh.

\begin{abstract}
Introduction: Dyslipidemia is measured to be one among the 5 top most threatening factors for cardio-vascular diseases, along with hypertension, diabetes mellitus, smoking and obesity. Plant seeds like flax seeds are easy to consume and more effective in dyslipidemic patients. Therefore, this study is intended to conclude whether flax seed powder has any dose response on clinical variables associated with dyslipidemia in dyslipidemic patients.

Aim: To study the impact of supplementation of flax seed powder on the lipid levels as well as on the nutritional status of dyslipidemic patients.

Methodology: A private hospital, Galaxy Specialty Centre, Jaipur was selected to conduct the study. Total 100 dyslipidemic patients of age between 30 and 55 years were selected and 50 patients were given flax seed powder 15 grams per day for three months and 50 patients were kept as control. Anthropometric measurements and biochemical estimations were measured at pre and post intervention.

Results: After three months of supplementation with flax seed powder, there were significant improvements observed in the anthropometric measurements like weight, waist, hip circumference and BMI of the dyslipidemic patients. However, no changes were observed in control group. The lipid levels of the experimental group were found to be reduced significantly. The high density lipoprotein cholesterol was also increased in experimental group whereas in control group it was almost same.

Conclusion: The results indicate that intervention with flax seed powder may be regarded a useful remedial food for the management of dyslipidemia.
\end{abstract}

Keywords: Dyslipidemia; Total Cholesterol; Low Density Lipoprotein Cholesterol; Triglycerides; High Density Lipoprotein Cholesterol; Flax Seeds; Body Mass Index

\section{Introduction}

The prevalence of non-contagious diseases, including obesity, diabetes, cardiovascular disease (CVD), chronic respiratory diseases, hypertension, cancers and mental illness is increasing in epidemic magnitude globally with excessively higher rates in developing countries [1]. CVDs are the main widespread reason of mortality as well as morbidity in both under developed and highly developed countries and India is no exception Gupta., et al. [2]. Dyslipidemia is strongly related to the pathophysiology of cariovascular diseases. It is a well-known determinant for CVD [3]. The term dyslipidemia describes the abnormal levels of the lipoproteins such as higher levels of triglycerides (TGs) in serum or LDL-C or low levels of HDL-C. There are some primary causes of dyslipidemia that include the over production and poor clearance of the total choles- 
terol, triglycerides and LDL-cholesterol because of the mutations of single or a number of genes. The secondary causes consist of inactive way of life and disproportionate ingestion of trans fats, saturated fat and cholesterol. Some other associated core causes are diabetes mellitus, hypothyroidism, chronic kidney disease, alcohol abuse, liver diseases etc [4].

\section{Prevalence of dyslipidemia}

Global

The global occurrence of dyslipidemia differentiates among folks on the basis of their race, genetics, age, income level and other factors. In the developing cities, dyslipidemia prevalence is increasing significantly as the economy is growing [5].

One another study concluded that there was 34\% prevalence of dyslipidemia amongst Chinese population. It was found to be elevated in males by $41.9 \%$ and in females by $32.5 \%$ [6]. Wong., et al. [7] also described in their study on Chinese people about the incidences of dyslipidemia and summarized that $56 \%$ of the adults were dyslipidemic and many factors were associated with dyslipidemia such as higher age, femininity, urban areas, elevated BMI, high earnings, increased diastolic BP and amount of glucose in blood and smoking. According to a Canadian Health Measures Survey (2007-2009), 45\% of Canadians of age group 18-79 had dyslipidemia [8]. One more study suggested that dyslipidemia is certainly linked with age and body mass index. Among 4309 subjects, total cholesterol was found in $43 \%$, low HDL cholesterol was in $41.5 \%$, high LDL cholesterol was in $36.2 \%$, and high triglycerides levels were found in $35.7 \%$. Overall, $78.7 \%$ of men and $80.4 \%$ of women had at least 1 lipid abnormality [9].

India

Numerous studies describe that dyslipidemia incidences in Indians have been rising gradually with the passing of each decade. A study was conducted to estimate the prevalence of dyslipidemia among 200 Delhi residents. The findings of the study suggested that among 200 subjects, the increased total cholesterol levels ( $\geq 200 \mathrm{mg} \%$ ) was in $34 \%$, 38\% were having increased low-density lipoprotein levels ( $\geq 130 \mathrm{mg} \%$ ) and $40 \%$ of the subjects had elevated triglyceride ( $\geq 150 \mathrm{mg} \%$ ), and LDL cholesterol levels were found in $42 \%$ ( $<40 \mathrm{mg} \%$ ) [10]. One another study conducted in Punjab indicated that over one fourth $(27 \%)$ of the subjects have either increased total cholesterol or triglyceride levels. About $9.8 \%$ of the subjects were having hypercholesterolemia and $21.6 \%$ were diagnosed with hypertriglyceridemia [11]. A recent study by Das and Banik [12] in southern district of Bangladesh suggested that dyslipidemia occurrence was $73 \%$ in men while in women it was $71 \%$.
Indian medicinal plants have potent effects in treating diseases such as dyslipidemia. A variety of food sources are currently gaining attention globally for potential health benefits in the treatment of many diseases, such as dyslipidemia and related complications. Flax seed is among one of those conventional health food. Flax seeds had been noticed to possess antioxidant properties which act against many diseases like atherosclerosis, diabetes mellitus, hypertension, chronic inflammation and pre-cancerous stage. Flax is well known as a super food because it has many valuable nutrients such as alpha-linolenic acid, lignin and polysaccharides, all of these have beneficial effects in the prevention of diseases. Whole flax seed contain a total of $28 \%$ dietary fibre which consists of 7 to $10 \%$ soluble and 11 to $18 \%$ insoluble fibre, $40 \%$ of fats in which $57 \%$ is omega 3 fatty acids and $21 \%$ proteins. Changes in life style, weight management, increasing physical activity and healthy nutrition are very important for dyslipidemic patients to maintain their life quality. Although many drugs and intervention are available to manage dyslipidemia, in most instances these are expensive (like statins), for a developing country like India, and have adverse effects also. Botanical products can improve lipid levels and the overall condition of individuals with dyslipidemia. Therefore, the current study is intended to determine whether flax seed powder has any dose response on clinical variables associated with dyslipidemia in dyslipidemic patients.

\section{Objectives of the Study}

To assess the impact of administration of flax seed powder on nutritional status of dyslipidemic patients with respect to anthropometry and biochemical profile.

\section{Methodology}

A private hospital in Jaipur city was selected for the study. About 100 patients of dyslipidemia in the age group between 30 and 55 years, from the outpatient department of the hospital were selected for the study. Informed consent forms were collected from the patients. The approval from the ethics committee was obtained for carrying out intervention on dyslipidemic patients. Out of 100 patients 50 patients were given flax seed powder 15 grams per day along with diet counselling for three months. And 50 patients were kept as control group and given only diet counselling.

At the baseline, information regarding demographic profile, anthropometry (weight, height, waist and hip circumference) and lipid levels were obtained.

At post intervention data was collected on anthropometric indices such as weight and height, waist and hip circumference and lipid profile. 
Criteria for sample selection

Inclusion criteria

- Patients of age group $\geq 30$ years to $\leq 55$ years.

- Willingness to participate in the study.

- $\quad$ Patients of both the sexes.

- Patients with body mass index $\geq 20 \mathrm{~kg} / \mathrm{m}^{2}$ to $\leq 35 \mathrm{~kg} / \mathrm{m}^{2}$.

- Presence of 2 indicators given below.

- Patients having total cholesterol $\geq 200 \mathrm{mg} / \mathrm{dl}$.

- Patients with low density lipoprotein cholesterol $\geq 130 \mathrm{mg} /$ dl.

- Patients with high density lipoprotein cholesterol $<40 \mathrm{mg} /$ dl.

- Patients with triglyceride levels $\geq 150 \mathrm{mg} / \mathrm{dl}$.

\section{Exclusion criteria}

- Patients suffering from severe diabetic complication as retinopathy, nephropathy, neuropathy etc.

- Patients having severe cardiac complications as ischemic heart disease, myocardial infarction, cardiovascular disease.

- Pregnant or lactating women.

- Patients with known hypersensitivity to the supplement.

- Not willing to participate.

\section{Biochemical tests}

The blood samples was collected and analysed. Blood serum was used for the analysis of triglycerides, total cholesterol, HDL and LDL cholesterol at baseline (day 0) and after 3 months of supplementation. Blood sample was obtained after 12 hour overnight fasting.

\section{Statistical analysis}

Data was tabulated and computed. Mean, median and standard deviation was calculated. Difference in the various parameters of intervention was assessed by using ' $t$ ' test.

\section{Results and Discussion}

After three months of supplementation with flax seed powder, there was significant reduction in weight $(\mathrm{t}-4.620, \mathrm{p}<.000)$, body mass index ( $\mathrm{t}-4.463, \mathrm{p}<.000)$, waist circumference $(\mathrm{t}-3.855, \mathrm{p}<$ $.000)$ and hip circumference $(\mathrm{t}-3.454, \mathrm{p}<.001)$ of the dyslipidemic patients whereas the reduction in control group was not found to be significant.

The reduction in the levels of total cholesterol (t- 6.210, $\mathrm{p}<$ $.000)$, triglycerides $(\mathrm{t}-7.116, \mathrm{p}<.000)$, LDL $(4.646, \mathrm{p}<.000)$ and

\begin{tabular}{|c|c|c|c|c|c|c|}
\hline \multirow{2}{*}{\multicolumn{3}{|c|}{ Variables }} & \multicolumn{2}{|c|}{ Control } & \multicolumn{2}{|c|}{ Powder } \\
\hline & & & \multirow{2}{*}{$\begin{array}{c}\text { Mean } \\
168.9\end{array}$} & \multirow{2}{*}{$\frac{\text { S.D }}{6.578}$} & \multirow{2}{*}{\begin{tabular}{|c|} 
Mean \\
167.88
\end{tabular}} & \multirow{2}{*}{$\begin{array}{c}\text { S.D } \\
7.592\end{array}$} \\
\hline \multirow{4}{*}{$\begin{array}{l}\text { Height } \\
(\mathrm{cm})\end{array}$} & \multicolumn{2}{|c|}{ Baseline } & & & & \\
\hline & \multicolumn{2}{|c|}{ Follow-up } & 168.9 & 6.578 & 167.88 & 7.591 \\
\hline & \multirow{2}{*}{ Paired T test } & T value & & & & \\
\hline & & p-value & & & & \\
\hline \multirow{4}{*}{$\begin{array}{l}\text { Weight } \\
\text { (kg) }\end{array}$} & \multicolumn{2}{|c|}{ Baseline } & 84.4 & 13.59 & 81.74 & 15.518 \\
\hline & \multicolumn{2}{|c|}{ Follow-up } & 84.11 & 13.443 & 79.68 & 15.076 \\
\hline & \multirow{2}{*}{ Paired $\mathrm{T}$ test } & $\mathrm{T}$ value & \multicolumn{2}{|c|}{1.123} & \multicolumn{2}{|c|}{4.62} \\
\hline & & $\mathrm{p}$-value & \multicolumn{2}{|c|}{0.267} & \multicolumn{2}{|c|}{0} \\
\hline \multirow{4}{*}{ BMI } & \multicolumn{2}{|c|}{ Baseline } & 29.54 & 4.06 & 29.03 & 4.415 \\
\hline & \multicolumn{2}{|c|}{ Follow-up } & 29.5 & 4.003 & 28.31 & 4.272 \\
\hline & \multirow{2}{*}{ Paired $\mathrm{T}$ test } & $\mathrm{T}$ value & \multicolumn{2}{|c|}{0.224} & \multicolumn{2}{|c|}{4.463} \\
\hline & & $\mathrm{p}$-value & \multicolumn{2}{|c|}{0.824} & \multicolumn{2}{|c|}{0} \\
\hline \multirow{4}{*}{$\begin{array}{l}\mathrm{HC} \\
(\mathrm{cm})\end{array}$} & \multicolumn{2}{|c|}{ Baseline } & 108.52 & 8.375 & 106.35 & 11.158 \\
\hline & \multicolumn{2}{|c|}{ Follow-up } & 108.36 & 8.419 & 105.27 & 11.36 \\
\hline & \multirow{2}{*}{ Paired T test } & $\mathrm{T}$ value & \multicolumn{2}{|c|}{1.168} & \multicolumn{2}{|c|}{3.454} \\
\hline & & p-value & 0.2 & & & 01 \\
\hline & Baseli & & 113.3 & 8.326 & 109.01 & 11.713 \\
\hline WC & Follow & -up & 113.07 & 8.352 & 107.45 & 11.684 \\
\hline$(\mathrm{cm})$ & Daired T to & $\mathrm{T}$ value & & & & 55 \\
\hline & fantea I tes & p-value & $0 .($ & & & 0 \\
\hline & Baseli & & 1.04 & 0.029 & 1.02 & 0.048 \\
\hline & Follow & -up & 1.04 & 0.028 & 1.02 & 0.044 \\
\hline & & $\mathrm{T}$ value & & & & 85 \\
\hline & I ancus & p-value & & & & 44 \\
\hline
\end{tabular}

Table 1: Mean anthropometric measurements of dyslipidemic patients from pre to post intervention.

VLDL ( $\mathrm{t}-7.403, \mathrm{p}<.000)$ was statistically significant in the powder group however, reduction in total cholesterol, triglycerides, LDL levels was also seen in control group but VLDL levels was not found to be reduced in the control group. The mean HDL level was found to be increased in powder group from $41.43 \mathrm{mg} / \mathrm{dl}$ to $42.91 \mathrm{mg} / \mathrm{dl}$ however, in control group the level of HDL was almost same.

\section{Conclusion}

The results of the current trial revealed that after supplementation of flax seeds, there was remarkable reduction in lipid levels and anthropometric indices of dyslipidemic patients. The improvements were seen in weight, BMI, waist and hip circumference of the patients. There was significant improvement observed in the total cholesterol levels, low density lipoprotein cholesterol, triglyc- 


\begin{tabular}{|c|c|c|c|c|c|c|}
\hline \multirow{2}{*}{\multicolumn{2}{|c|}{ Variables }} & \multicolumn{2}{|c|}{ Control } & \multicolumn{3}{|c|}{ Powder } \\
\hline & & \multirow{2}{*}{\begin{tabular}{|c|} 
Mean \\
259.62 \\
\end{tabular}} & \multicolumn{2}{|c|}{ S.D } & \multirow{2}{*}{\begin{tabular}{r|} 
Mean \\
44.5
\end{tabular}} & \multirow{2}{*}{$\begin{array}{l}\text { S.D } \\
98\end{array}$} \\
\hline \multirow{4}{*}{$\begin{array}{l}\text { Total } \\
\text { Choles- } \\
\text { terol } \\
(\mathrm{mg} / \mathrm{dl})\end{array}$} & Baseline & & 35.085 & 236.42 & & \\
\hline & Follow-up & 236.15 & 45.365 & 193.89 & 38.5 & 546 \\
\hline & \multirow{2}{*}{\begin{tabular}{c|c} 
Paired & T value \\
T test & $\mathrm{p}$-value
\end{tabular}} & \multicolumn{2}{|c|}{5.69} & \multicolumn{3}{|c|}{6.21} \\
\hline & & \multicolumn{2}{|c|}{0} & \multicolumn{3}{|c|}{0} \\
\hline \multirow{4}{*}{$\begin{array}{l}\text { Triglyc- } \\
\text { erides } \\
(\mathrm{mg} / \mathrm{dl})\end{array}$} & Baseline & 267.83 & 67.543 & 268.53 & 88.3 & 389 \\
\hline & Follow-up & 247.03 & 61.771 & 186.3 & 74.5 & 25 \\
\hline & \multirow{2}{*}{\begin{tabular}{|c|c|c} 
Paired & T value \\
T test & $p$-value
\end{tabular}} & \multicolumn{2}{|c|}{3.029} & \multicolumn{3}{|c|}{7.116} \\
\hline & & \multicolumn{2}{|c|}{0.004} & \multicolumn{3}{|c|}{0} \\
\hline \multirow{4}{*}{$\begin{array}{l}\mathrm{HDL} \\
(\mathrm{mg} / \mathrm{dl})\end{array}$} & \begin{tabular}{|l|} 
Baseline \\
\end{tabular} & 39.5 & 6.197 & 41.43 & 26.6 & 503 \\
\hline & Follow-up & 39.97 & 4.473 & 42.91 & 6.8 & \\
\hline & Paired $\mathrm{T}$ value & \multicolumn{2}{|c|}{-0.716} & \multicolumn{3}{|c|}{-0.411} \\
\hline & T test $\mathrm{p}$-value & \multicolumn{2}{|c|}{0.477} & \multicolumn{3}{|c|}{0.683} \\
\hline \multirow{4}{*}{$\begin{array}{l}\mathrm{LDL} \\
(\mathrm{mg} / \mathrm{dl})\end{array}$} & Baseline & 166.78 & 31.531 & 143.95 & 44.6 & 524 \\
\hline & Follow-up & 148.74 & 45.657 & 114.11 & 33. & \\
\hline & Paired $\mathrm{T}$ value & \multicolumn{2}{|c|}{4.023} & \multicolumn{3}{|c|}{4.646} \\
\hline & T test $p$-value & \multicolumn{2}{|c|}{0} & \multicolumn{3}{|c|}{0} \\
\hline \multirow{4}{*}{$\begin{array}{l}\text { VLDL } \\
(\mathrm{mg} / \mathrm{dl})\end{array}$} & Baseline & 53.32 & 13.582 & 53 & .7 & 17.702 \\
\hline & Follow-up & 52.19 & 21.517 & 36. & 98 & 14.65 \\
\hline & Paired $\mathrm{T}$ value & \multicolumn{2}{|c|}{0.365} & \multicolumn{3}{|c|}{7.403} \\
\hline & T test $p$-value & \multicolumn{2}{|c|}{0.716} & \multicolumn{3}{|c|}{0} \\
\hline
\end{tabular}

Table 2: Mean biochemical estimations of dyslipidemic patients from pre to post intervention.

erides and very low density lipoprotein cholesterol levels. Hence, the atherogenic indices were also found to be improved. Therefore, the study concluded that three months supplementation of flax seed powder managed the anthropometric indices, lipid profile and overall condition of dyslipidemic patients, thus exhibiting cardio protective effects. Moreover, Flax seeds are good and proposed to be as alternatives to hypolipidemic drugs.

\section{Bibliography}

1. Terzic A and Waldman S. "Chronic Diseases: The Emerging Pandemic". Clinical and Translational Science 4.3 (2011): 225226.

2. Gupta A., et al. "Prevalence of diabetes and cardiovascular risk factors in middleclass urban participants in India". BMJ Open Diabetes Research and Care 2 (2014): e000048.

3. Sharma Y K., et al. "Prevalence of risk factors for coronary artery disease in an urban Indian Population". BMJ Open 4 (2014): e005346.
4. Goldberg AC. Dyslipidemia. MSD, Professional Version, www. msdmanual.com (2015).

5. İlhan C., et al. "Serum lipid and lipoprotein levels, dyslipidemia prevalence, and the factors that influence these parameters in a Turkish population living in the province of Tokat". Turkish Journal of Medical Sciences 40.5 (2010): 771-782.

6. Pan L., et al. "The prevalence, awareness, treatment and control of dyslipidemia among adults in China". China National Survey of Chronic Kidney Disease Working Group Elsevier. Atherosclerosis 248 (2016): 2-9.

7. Wang S., et al. "High Prevalence and associated factors of dyslipidemiain the adult chinese population". Plos ONE 6.I-3 (2011): e17326.

8. Joffres M D., et al. "Dyslipidemia Prevalence, Treatment, Control, and Awareness in the Canadian Health Measures Survey". Canadian Journal of Public Health 104 (2013): 252-e257.

9. Bayram F., et al. "Prevalence of dyslipidemia and associated risk factors in Turkish adults". Journal of Clinical Lipidology 8.2 (2014): 206-216.

10. Sharma U., et al. "Dyslipidemia and associated risk factors in a resettlement colony of Delhi". Journal of Clinical Lipidology 7.6 (2013): 653-660.

11. Tripathy J P., et al. "Burden and risk factors of dyslipidemiaresults from a STEPS survey in Punjab India Diabetes and Metabolic Syndrome". Clinical Research and Reviews 11.1 (2017): S21-S27.

12. Das $\mathrm{H}$ and Banik S. "Prevalence of dyslipidemia among the diabetic patients in southern Bangladesh: A cross-Sectional Study". Diabetes, Metabolic Syndrome and Obesity: Targets and Therapy 13.1 (2019): 252-257.

\section{Volume 5 Issue 9 September 2021 (C) All rights are reserved by Deepika Sharma and Nimali Singh.}

